\title{
Análise da energia de compactação de um solo com adição de agregado reciclado da construção civil
}

Barros, D. C. F.

Escola Politécnica de Pernambuco

Universidade de Pernambuco

50.720-001 - Recife, Brasil

Diogocesar_@hotmail.com
Lafayett, K. P. V.

Escola Politécnica de Pernambuco

Universidade de Pernambuco

50.720-001 - Recife, Brasil

Resumo O presente trabalho visa avaliar a influência da energia de compactação no comportamento mecânico de um agregado reciclado, estudando sua aplicação em obras de pavimentação. Desta forma, foram realizados ensaios de laboratório com solo da formação Barreiras, coletado no município do Cabo de Santo Agostinho (RMR), com agregado reciclado de alvenaria coletado em uma obra residencial da cidade do Recife e duas misturas destes materiais. A partir dos resultados obtidos, os quais possibilitaram desde a classificação do agregado reciclado como misto e predominantemente arenoso e do solo areno-argiloso até a percepção do agregado reciclado como mais sensivel às energias de compactação aplicadas, concluiu-se que a alternativa de aplicação de agregados reciclados em obras de pavimentação mostra-se relevante e viável, já que algumas composições como a de $50 \%$ de solo, $48 \%$ de AR e $2 \%$ de cimento atendem aos requisitos avaliados na pesquisa para aplicação em algumas camadas do pavimento.

\footnotetext{
Abstract This study aims to evaluate the energy of compactation influence on the mechanical behaviour of a recycled aggregate, studying its application in paving. Thus, soil from "Barreiras" formation, collected in the city of Cabo de Santo Agostinho (RMR), recycled aggregate of the masonry collected in a residential project in the city of Recife and two mixtures of these materials were submitted to laboratory tests. From the results obtained, which allowed the classification of the aggregate and recycled as mixed and predominantly sandy and the soil as sandy-clay and also the perception of the recycled aggregate as more responsive to the applied compaction, it was concluded that the alternative application of recycled aggregates in paving proves relevant and viable, since some compositions as $50 \%$ soil, $48 \%$ of RA and $2 \%$ cement satisfy the requirements evaluated in this research for application in a few layers of the pavement.
} 


\section{Introdução}

A indústria da construção civil tem grande importância para o meio econômico e social do planeta. As atividades do setor, contudo, desde a antiguidade, trazem grandes impactos para o meio ambiente, por consumir recursos naturais e gerar quantidade significativa de resíduos.

A partir da década de 70 , iniciaram-se as primeiras mobilizações internacionais para tratar da questão ambiental, mas foi a partir da reunião de 1992, a ECO92, que foi implantado o princípio do "desenvolvimento sustentável". A adoção do conceito que integra desenvolvimento com proteção ao meio ambiente no meio construtivo, torna-se, portanto, fundamental, já que ele consome entre $14 \%$ e $50 \%$ dos recursos naturais extraídos no planeta [1].

Com base no ponto de vista do desenvolvimento sustentável, a utilização de resíduos da construção e demolição (RCC) mostra-se como uma das principais formas de mitigar os impactos ambientais gerados pelo setor. Pesquisas com este enfoque são cada vez mais frequentes no meio acadêmico e profissional, pois, além de diminuir o consumo dos recursos naturais e consequentemente a geração de resíduos, é uma solução para o problema da deposição irregular dos mesmos.

Dentre as diversas formas de aplicação do RCC, está a utilização em obras de pavimentação, a qual é estudada neste trabalho. É cada vez maior o interesse em pesquisas com o tema no Brasil, já que o cenário apresenta-se com grande carência de pavimentação da malha rodoviária e que este é o principal transporte de cargas e passageiros do país [2]. Além disso, outro atrativo é a questão econômica, pois os agregados reciclados são vendidos a preços inferiores aos granulares normalmente empregados na pavimentação [3].

\section{Objetivos}

O nosso objetivo com a pesquisa é dar continuidade aos trabalhos realizados com a avaliação do comportamento mecânico do agregado reciclado, a partir da utilização de diferentes energias de compactação, observando os requisitos para aplicação em obras de pavimentação.

\section{Revisão bibliográfica}

\subsection{Resíduos de Construção e Demolição (RCC)}

De acordo com a resolução $\mathrm{n}^{\circ} 307$ do Conselho Nacional do Meio Ambiente (CONAMA), os resíduos de construção e demolição são os oriundos de construções, reformas, reparos e demolições, assim como os resultantes da preparação e escavação de terrenos, tais como: tijolos, blocos cerâmicos, concreto em geral, solos, rochas, metais, resinas, colas, tintas madeiras e compensados, forros argamassa, gesso telhas, pavimento asfáltico, vidros, plásticos, tubulações, fiação elétrica etc. Além disso, eles são classificados como:

Classe A - resíduos reutilizáveis ou recicláveis como agregados;

Classe B - resíduos recicláveis para outras destinações;

Classe C - resíduos para os quais não foram desenvolvidas tecnologias ou aplicações economicamente viáveis;

Classe D - resíduos perigosos oriundos ou prejudiciais à saúde [4].

\subsection{Legislação}

Devido ao acelerado crescimento da indústria de construção e da consequente produção de RCC, iniciou-se o sério problema da deposição irregular de resíduos nos centros urbanos. Tornou-se necessária, portanto, a criação de uma legislação e fiscalização firmes para tratar da gestão dos resíduos.

O cenário brasileiro passou por mudanças positivas na questão ambiental a partir da elaboração da resolução $\mathrm{n}^{\circ}$ 307 do CONAMA em 2002 e de uma série de normas regulamentadoras sobre gerenciamento a aproveitamento de RCC com início em 2004, as quais tiveram por objetivo a implantação de diretrizes, critérios e procedimentos para a gestão dos resíduos da construção civil, assim como as ações necessárias para minimizar os impactos ambientais. Dentre as determinações, pode-se destacar a proibição da disposição irregular dos resíduos e sua destinação adequada de acordo com a classificação do resíduo e a implementação do Plano Integrado de Gerenciamento de Resíduos da Construção Civil, o qual deve ser elaborado pelos Municípios e Distrito Federal.

\subsection{Geração de Resíduos}

No Brasil, foram gerados cerca de 33 milhões de toneladas de resíduos de construção e demolição em 2011 [5]. A geração exagerada de RCC tem provocado problemas de ordem econômica, social e ambiental, já que grande parte desse material é disposta de forma irregular em locais como vias, rios, córregos, terrenos baldios e áreas de mananciais [6]. 
Atualmente, os resíduos da construção civil produzidos na RMR são destinados a uma Área de Transbordo e Triagem localizada em Camaragibe, a Ciclo Ambiental, a qual recebe resíduo de Classe A e o reaproveita através da britagem, possibilitando seu retorno à cadeia produtiva. Segundo o SINDUSCON, contudo, apenas $5 \%$ dos RCC são transportados para a ATT citada [7].

\subsection{Reciclagem e Reuso do RCC}

A reciclagem dos $\mathrm{RCC}$ pode trazer vários benefícios, a exemplo da redução do consumo de recursos naturais não renováveis, da minimização de áreas destinadas para aterros, já que será dada uma utilidade para os resíduos, do menor consumo de energia durante o processo de produção de materiais de construção e da diminuição da poluição. Além destes, é notável o aproveitamento econômico, pois há uma diminuição dos gastos com a gestão dos resíduos e um menor consumo de materiais naturais com a possibilidade de reaproveitamento do RCC nos próprios canteiros de obra e a venda ou doação para instituições licenciadas.

Para que possa ser utilizado como material de construção, o RCC precisa ser classificado como do tipo A, segundo a Resolução ${ }^{\circ} 307$ do CONAMA e deve sofrer um processo de reciclagem para dar origem a um novo produto: o agregado reciclado de resíduo sólido da construção civil (AR) [8]. O beneficiamento do resíduo é feito através de processos de trituração e peneiramento do material graúdo.

\subsection{Uso em obras de pavimentação}

Nos últimos anos, tem se tornado crescente a utilização de agregados reciclados da construção civil e de demolição em camadas de base e sub-base de pavimentos [9]. O uso dos materiais alternativos é estimulado pelos altos custos, pela grande demanda dos agregados naturais e pelos impactos ambientais produzidos na extração, já que os agregados reciclados atuam como substitutos parciais ou totais dos agregados normalmente utilizados.

O uso do agregado reciclado em pavimentação mostrase, então, como uma alternativa muito interessante para a substituição dos materiais naturais, não-renováveis, já que milhares de quilômetros de vias brasileiras ainda não são pavimentadas. De fato, de acordo com dados do Departamento Nacional de Infraestrutura de Transportes (DNIT), em 2012, 80\% da malha rodoviária brasileira não é pavimentada, contabilizando cerca de $1.359 .061 \mathrm{~km}$.
Entretanto, torna-se necessário levar em consideração a heterogeneidade do resíduo, fenômeno que pode acarretar em comportamentos diferentes dos agregados naturais normalmente empregados em pavimentação.

\section{Metodologia}

Por não existir normas técnicas específicas para a realização de ensaios de laboratório com RCC, foram utilizadas as normas da Associação Brasileira de Normas Técnicas (ABNT) e do Departamento Nacional de Infraestrutura e Rodagens (DNIT), as quais prescrevem os métodos para utilização de amostras de solos.

\subsection{Materiais}

A seleção do solo foi baseada pela facilidade de obtenção e por existir algumas pesquisas na área, como a tese de doutorado de Lafayette (2006), onde foram estudados solos da Formação Barreiras e Solos residuais de Granito. Foram descartados solos contendo matéria orgânica e muito óxido de ferro, e solos que, após sua compressão na mão, se esfarelassem, caracterizando um alto teor de areia, pois quando incorporados ao agregado reciclado estes teores iriam ficar muito mais elevados.

Foi coletado solo localizado no município do Cabo de Santo Agostinho (RMR). A amostra obtida foi armazenada em sacos plásticos e transportada para o Laboratório Avançado de Construção Civil (LACC) da Escola Politécnica de Pernambuco. A Figura 1 apresenta a área na qual foi retirada a amostra de solo para os ensaios de laboratório.

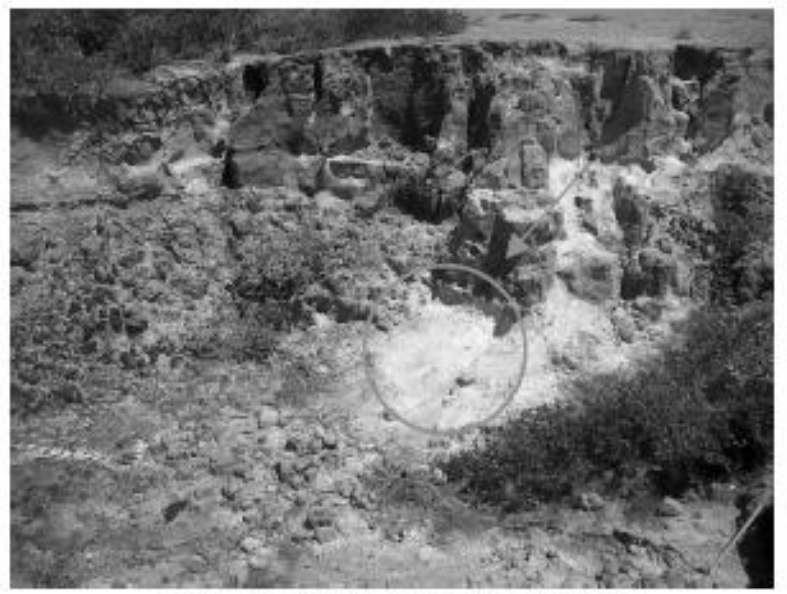

Fig. 1. Local de coleta do solo

A coleta de RCC foi feita em uma obra residencial da Cidade do Recife, na fase de alvenaria. O total de material coletado foi de $619,69 \mathrm{~kg}$, como mostra a Figura 2. Todo o resíduo foi transportado em bombonas e armazenado no 
Laboratório Avançado de Construção Civil (LACC) da Escola Politécnica de Pernambuco.

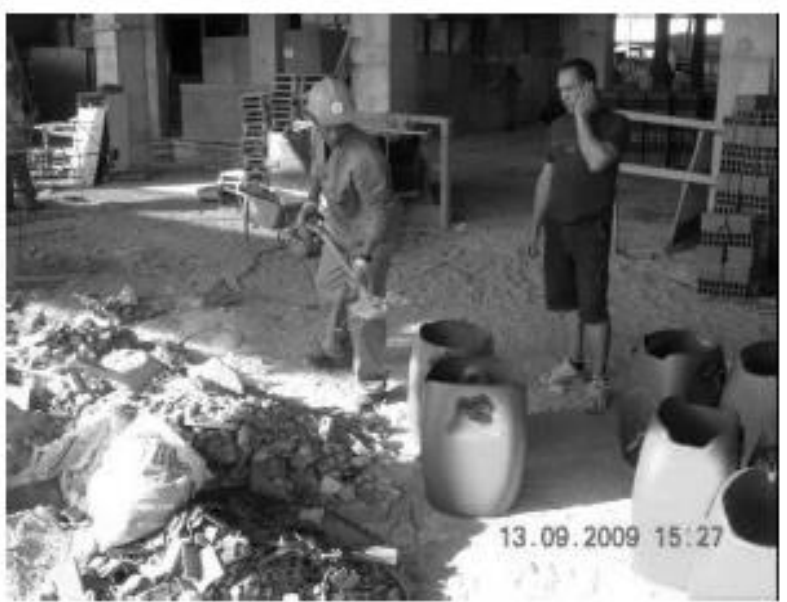

Fig. 2. Coleta de amostras do RCC

Devido à verificação de uma baixa resistência nos corpos de prova em misturas sem adição de cimento, surgiu o interesse de adicionar o material à composição. $\mathrm{O}$ cimento apresenta propriedades de aglomerante capaz de adquirir resistência a esforços mecânicos quando hidratado, por isso foi escolhido o cimento do tipo CP II - E 32 com o objetivo de ser adicionado na proporção de $2 \%$ à mistura solo e RCC e melhorar suas propriedades mecânicas. $\mathrm{O}$ teor de apenas $2 \%$ de cimento em relação ao peso seco da mistura foi considerado, porque uma quantidade maior de cimento inviabilizaria certas obras como de pavimentação sob o ponto de vista econômico [10]. Algumas características do cimento estudado podem ser encontradas na NBR 11578/91 [11]:

Tabela 1. Características do cimento da classe 32

\begin{tabular}{|c|c|c|c|}
\hline \multicolumn{2}{|c|}{$\begin{array}{c}\text { Características e } \\
\text { propriedades }\end{array}$} & $\begin{array}{l}\text { Unida- } \\
\text { de }\end{array}$ & $\begin{array}{c}\text { Classe } \\
32\end{array}$ \\
\hline \multirow[t]{2}{*}{ Finura } & $\begin{array}{c}\text { Residuo na } \\
\text { peneira } \\
75 \mu \mathrm{m}\end{array}$ & $\%$ & $\leq 12$ \\
\hline & $\begin{array}{c}\text { Área } \\
\text { especifica }\end{array}$ & $\mathrm{m}^{2} / \mathrm{kg}$ & $\geq 260$ \\
\hline \multicolumn{2}{|c|}{ Tempo de início de pega } & $\mathrm{h}$ & $\geq 1$ \\
\hline \multicolumn{2}{|c|}{ Expansibilidade a quente } & $\mathrm{mm}$ & $\leq 5$ \\
\hline \multirow{3}{*}{$\begin{array}{l}\text { Resistência } \\
\grave{a ̀} \\
\text { compressão }\end{array}$} & $\begin{array}{l}3 \text { dias de } \\
\text { idade }\end{array}$ & $\mathrm{MPa}$ & $\geq 10$ \\
\hline & $\begin{array}{l}7 \text { dias de } \\
\text { idade }\end{array}$ & $\mathrm{MPa}$ & $\geq 20$ \\
\hline & $\begin{array}{l}28 \text { dias de } \\
\text { idade }\end{array}$ & $\mathrm{MPa}$ & $\geq 32$ \\
\hline
\end{tabular}

\subsection{Benfica do RCC}

O beneficiamento consistiu na diminuição das partículas do resíduo com o auxílio de um britador de mandíbula. Para garantir que todo o material britado fosse menor que $4,8 \mathrm{~mm}$, foi utilizada uma peneira $\mathrm{n}^{\circ} 4$ junto ao britador. Depois de finalizado o beneficiamento, toda a amostra foi dividida em quatro partes iguais para realizar o processo de quarteamento. Após a homogeneização, todo o material foi armazenado em bombonas no LACC.

\subsection{Composição Gravimétrica}

A composição gravimétrica tem por objetivo conhecer as frações dos materiais constituintes. Para fazê-la, primeiramente peneirou-se o material contido nas bombonas, a fim de separar a parte graúda da miúda. Em seguida, lavou-se o material para retirar os finos da amostra e os grãos miúdos restantes. Após a secagem, foi realizada, então, a segregação do material através da observação. Por fim, foram pesadas as frações dos constituintes do RCC e obtida sua porcentagem em relação à massa total da amostra.

\subsection{Análise Granulométrica}

O ensaio foi realizado segundo a NBR 7181/84 [12]. Para a realização deste ensaio, foram separados $1500 \mathrm{~g}$ da amostra e passados na peneira $\mathrm{n}^{\circ} 10(2,0 \mathrm{~mm})$, para separar o material miúdo do graúdo (figura 3). Em seguida, lavouse na própria peneira o material graúdo retido, a fim de remover os grãos com dimensão inferior a $2,00 \mathrm{~mm}$ restantes e retirar os finos da amostra.

Do material passante, foram separados $70 \mathrm{~g}$, no caso do solo, ou $120 \mathrm{~g}$, no caso do AR, para a sedimentação e peneiramento fino, e ainda cerca de $100 \mathrm{~g}$ para determinação da umidade higroscópica em estufa à temperatura de $105^{\circ}$ $\mathrm{C}$ a $110^{\circ} \mathrm{C}$.

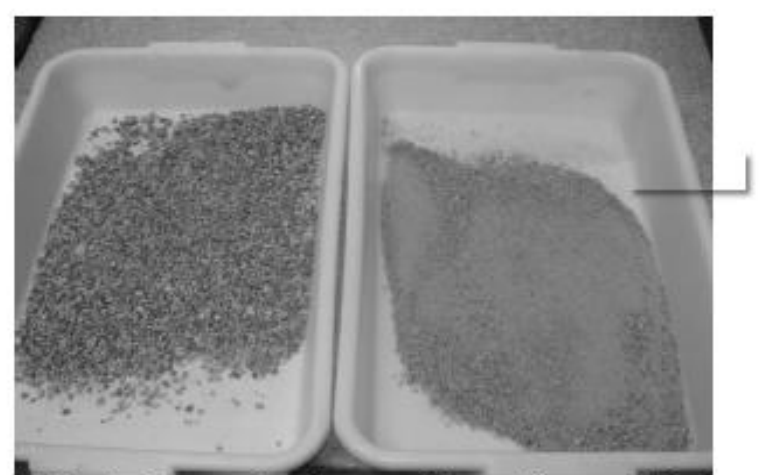

Fig. 3. Separação do material graúdo e miúdo 
Para o peneiramento do material miúdo utilizou-se a amostra resultante do ensaio de sedimentação. O material contido na proveta foi transferido para a peneira de $n^{\circ} 200$ e então lavado à baixa pressão, com o objetivo de remover o material pulverulento, ou seja, com grãos de diâmetro menor que $0,075 \mathrm{~mm}$ (figura 4). Posteriormente, o material retido foi levado para secagem na estufa até atingir constância de massa.

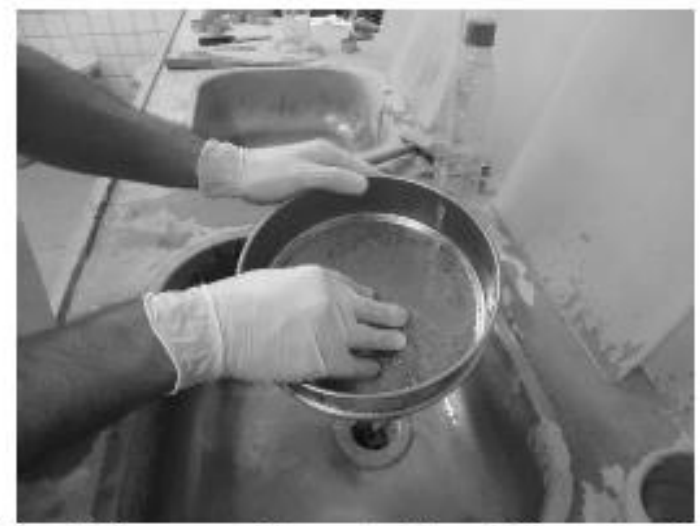

Fig. 4. Lavagem do material miúdo na peneira $\mathrm{n}^{\circ} 200$.

O peneiramento da fração graúda foi realizado nas peneiras $\mathrm{n}^{\circ} 4$ e $\mathrm{n}^{\circ} 10$, enquanto que a fração miúda foi peneirada na série de peneiras de números $16,30,40,50,100$ e 200.

Para a realização da sedimentação, separou-se a quantidade suficiente de material passante na peneira $\mathrm{n}^{\circ} 10$, e, em seguida, misturou-se, em um béquer com $125 \mathrm{ml}$ de água destilada, 5,71g do defloculante hexametafosfato de sódio. A solução preparada foi então adicionada à amostra e agitada com auxílio do bastão até homogeneizar a solução final. A função do defloculante foi de quebrar as ligações existentes entre os grãos do solo fino.

Em seguida, a solução foi mantida em repouso por 24h e, logo após, removeu-se todo o material da cápsula, colocando-o em um dispersor eletrônico. $\mathrm{O}$ material foi então transferido para uma proveta e esta foi completada com água destilada até atingir $1000 \mathrm{ml}$. A proveta foi então agitada por 1 minuto e colocada na bancada (Fig. 5), realizando-se as leituras com o densímetro para os tempos decorridos de $30 \mathrm{seg}$, $1 \mathrm{~min}, 2 \mathrm{~min}$, $4 \mathrm{~min}, 8 \mathrm{~min}, 15 \mathrm{~min}$, $30 \mathrm{~min}, 1 \mathrm{~h}, 2 \mathrm{~h}, 4 \mathrm{~h}, 8 \mathrm{~h}$ e $24 \mathrm{~h}$.

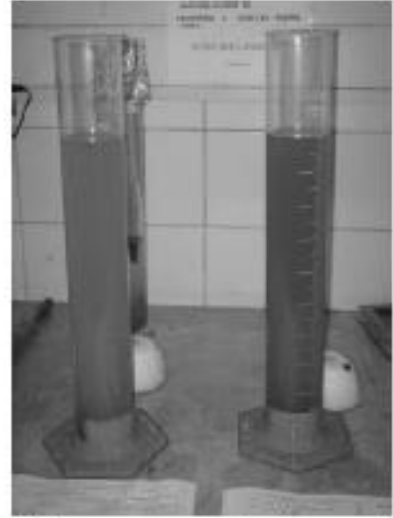

Fig. 5. Material nas provetas para sedimentação.

\subsection{Limites da Consistência}

O teor de umidade, por si só, não é suficiente para se determinar o estado das argilas. É necessário analisá-lo de acordo com os teores de umidades correspondentes a seus comportamentos. Esses teores são os limites de consistência ou limites de Atterberg (PINTO, 2006).

No presente estudo, foram determinados os limites de liquidez e plasticidade dos materiais avaliados, segundo as NBR's 6459 e 7180 de 1984 [13] [14].

\subsection{Massa especifica}

A massa específica do solo ou densidade real dos grãos $(\gamma s)$ é a relação entre as partículas sólidas e o seu volume. Este índice físico é determinado em laboratório e foi obtido com base na NBR 6508/84 [15].

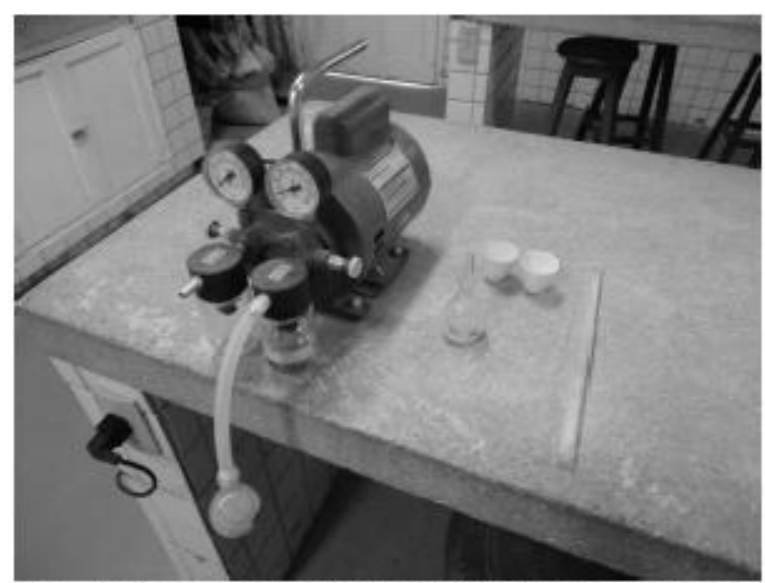

Fig. 6. Bomba de vácuo utilizada no ensaio de massa especifica. 


\subsection{Ensaios de Compactação}

Segundo Pinto (2006), a compactação dos solos tem em vista dois aspectos: aumentar o contato entre os grãos e torná-lo mais homogêneo. $\mathrm{O}$ aumento da densidade ou diminuição do índice de vazios é desejável não por si, mas devido ao melhoramento de diversas propriedades do solo, como o aumento da resistência e redução da permeabilidade [16].

Atualmente, a compactação dos solos é aplicada em diversas obras de engenharia, como a pavimentação, construção de barragens de terra, contenção de taludes e aterros em geral. Para isto, é necessário conhecer as características do solo, que são verificadas através de ensaios em laboratório.

Os ensaios de compactação foram executados, atendendo aos requisitos da NBR 7182/86 [17]. Todos as compactações foram realizadas com reuso de material e as amostras foram preparadas com secagem prévia até atingir a umidade higroscópica. As compactações foram realizadas em cilindro grande, para o solo, para o AR e para as misturas $50 \%$ solo $+50 \%$ AR e $75 \%$ solo $+25 \%$ AR.

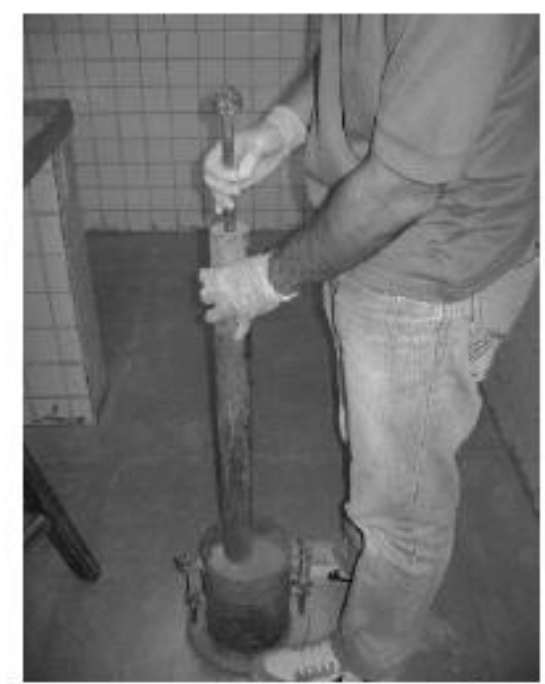

Fig. 7. Compactação do corpo-de-prova.

\subsection{Resistência à compactação Simples}

Os ensaios de resistência à compressão simples foram realizados com misturas de solo, AR e cimento, segundo a NBR 12770/92 [18], para energia de compactação intermediária, e segundo a NBR 12025/90 [19], para energia de compactação modificada. Os cilindros utilizados para moldagem possuíam as seguintes dimensões para altura e diâmetro respectivamente $5 \mathrm{~cm} \times 10 \mathrm{~cm}$ e $10 \mathrm{~cm} \times 12,8 \mathrm{~cm}$.

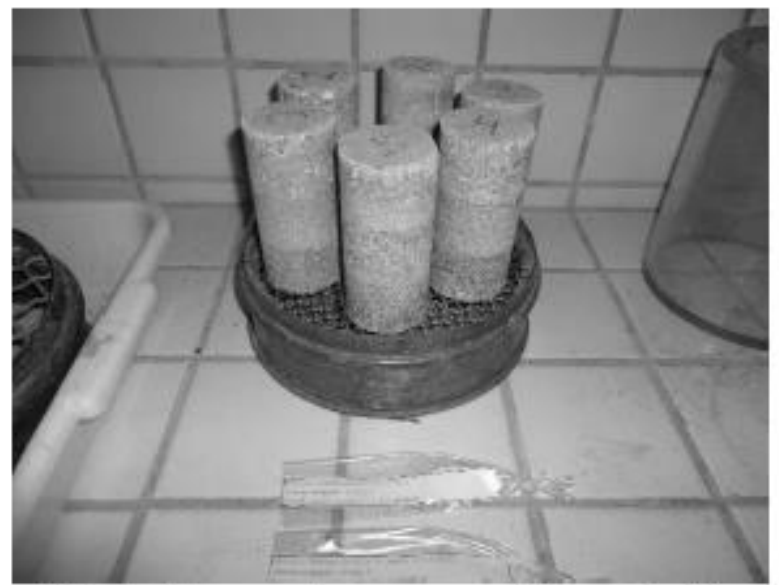

Fig. 8. Corpos-de-prova em câmara úmida

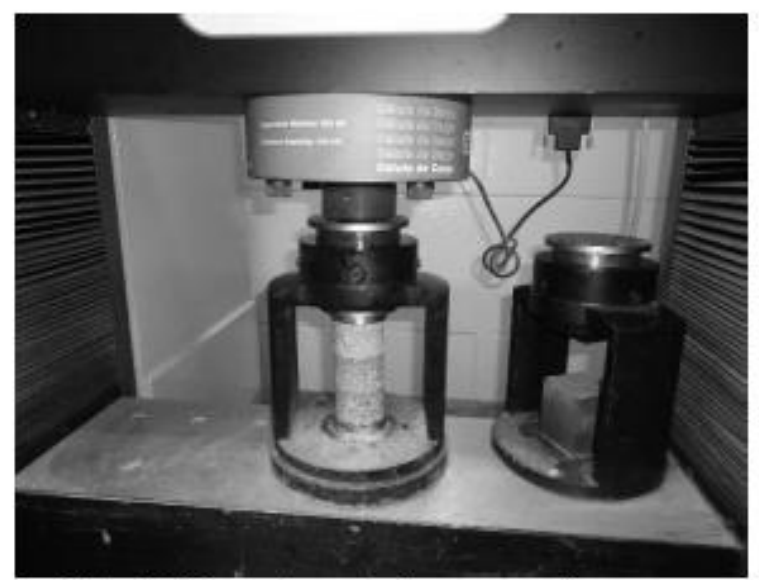

Fig. 9. Rompimento do corpos-de-prova

\section{Apresentação e análise dos resulta- dos}

A seguir serão abordados os resultados obtidos pelos ensaios de laboratório e suas respectivas análises das amostras de RCC na fase de alvenaria, de solo e das misturas destes materiais. 


\subsection{Composição Gravimétrica do RCC}

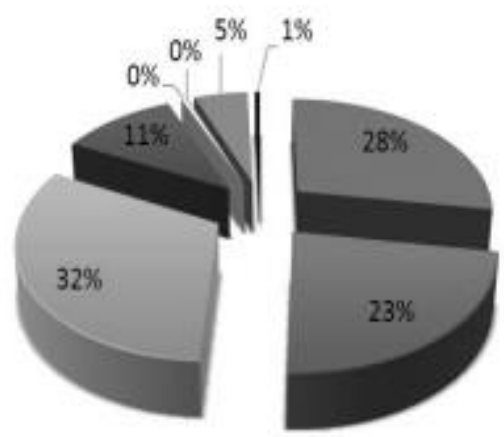

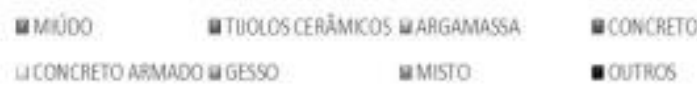

\section{Fig. 10. Composição Gravimétrica do RCC}

Através da análise da figura 10, pode-se observar que o RCC da fase de alvenaria é predominantemente composto por agregados miúdos, concreto, argamassa e material cerâmico, sendo $99 \%$ dos materiais constituintes da classe A. Então, o agregado reciclado pode ser classificado como "misto".

O teor de $1 \%$ de materiais indesejáveis, como gesso, plástico, papel, madeira, vidro e metal, é considerado admissível pela NBR 15115/2004 [20] para aplicação em obras de pavimentação.

\subsection{Análise Granulométrica}

$\mathrm{O}$ ensaio de granulometria do AR foi realizado antes e após a compactação com energia modificada. As curvas granulométricas estão apresentadas na figura 11 .

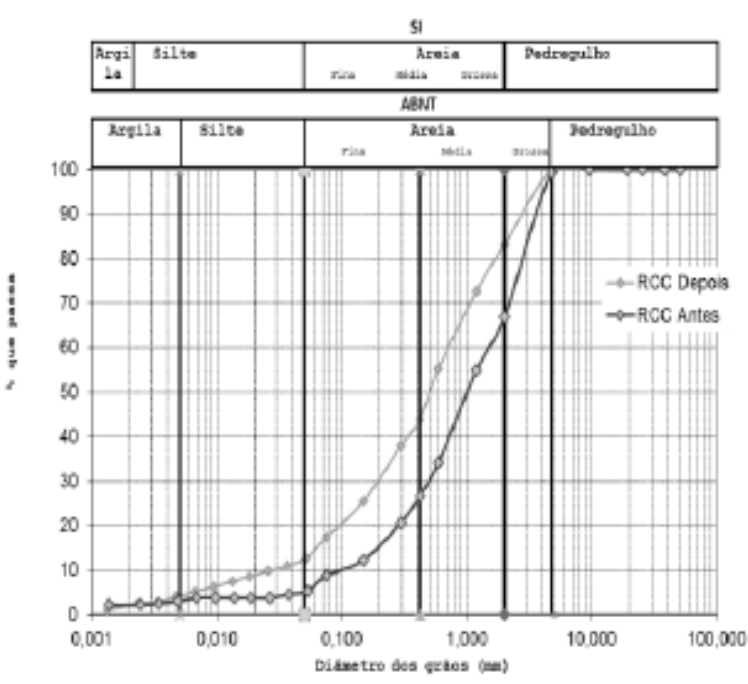

Fig. 11. Curvas granulométricas do AR antes e após compactação modificada.

Ao analisar a tabela 2, percebe-se que a areia é predominante na amostra de alvenaria, compondo aproximadamente $94 \%$ da amostra, o que evidencia as características de material arenoso apresentadas pelo AR. Resultados semelhantes foram encontrados em Macedo (2013) [10]. Em menor proporção, tem-se a argila e o silte em todas as amostras.

É possível concluir também que, para a compactação de energia modificada, houve uma significativa quebra dos grãos do AR. Este fenômeno pode ser explicado pela baixa resistência da fração de material cerâmico presente no RCC.

Tabela 2. Percentual de pedregulho, areia, silte e argila do AR, segundo ABNT.

\begin{tabular}{|c|c|c|c|c|}
\hline $\begin{array}{c}\text { Amos- } \\
\text { tra }\end{array}$ & $\begin{array}{c}\text { Pedregulho } \\
\mathbf{( \% )}\end{array}$ & $\begin{array}{c}\text { Areia } \\
\mathbf{( \% )}\end{array}$ & $\begin{array}{c}\text { Silte } \\
\mathbf{( \% )}\end{array}$ & $\begin{array}{c}\text { Argila } \\
\mathbf{( \% )}\end{array}$ \\
\hline AR & 0,76 & 93,99 & 2,14 & 3,12 \\
\hline $\begin{array}{c}\text { AR pós- } \\
\text { compac } \\
\text { tação }\end{array}$ & 0,02 & 87,45 & 8,37 & 4,16 \\
\hline
\end{tabular}

Foram avaliados também os coeficientes de uniformidade $(\mathrm{Cu})$ e curvatura $(\mathrm{Cc})$ do agregado reciclado, assim como a porcentagem de material passante na peneira $\mathrm{n}^{\circ} 40$ $(0,42 \mathrm{~mm})$, a fim de classifica-lo quanto à granulometria $\mathrm{e}$ mensurar a quantidade de finos da amostra. O agregado reciclado de alvenaria pôde, então, ser classificado como bem graduado e, tendo em vista a NBR 15116/2004 [21], 
atendente aos requisitos para utilização em obras de pavimentação do ponto de vista da granulometria (tabela 3 ).

Tabela 3. Porcentagem passante na peneira $0,42 \mathrm{~mm}$, coeficientes de uniformidade e curvatura do $A R$

\begin{tabular}{|l|l|l|l|}
\hline Amostra & $\begin{array}{c}\text { Porcentagem } \\
\text { passante na } \\
\text { peneira } \\
\mathbf{0 , 4 2 m m ~ ( \% ) ~}\end{array}$ & $\mathbf{C u}$ & $\mathbf{C c}$ \\
\hline AR & 26,69 & 15,18 & 1,59 \\
\hline $\begin{array}{l}\text { NBR } \\
\mathbf{1 5 1 1 6}\end{array}$ & 10 a 40 & $>10$ & $\begin{array}{l}\text { Não } \\
\text { consta }\end{array}$ \\
\hline
\end{tabular}

Para o solo, a análise granulométrica demonstrou que, apesar de a fração argilosa ser próxima de $50 \%$, o solo é predominantemente arenoso, sendo classificado como areno-argiloso. Constatou-se também que as porcentagens de silte e pedregulho são baixas. As amostras de solo não apresentaram coeficiente de uniformidade $(\mathrm{Cu})$ e curvatura $(\mathrm{Cc})$, devido a sua fração elevada de argila.

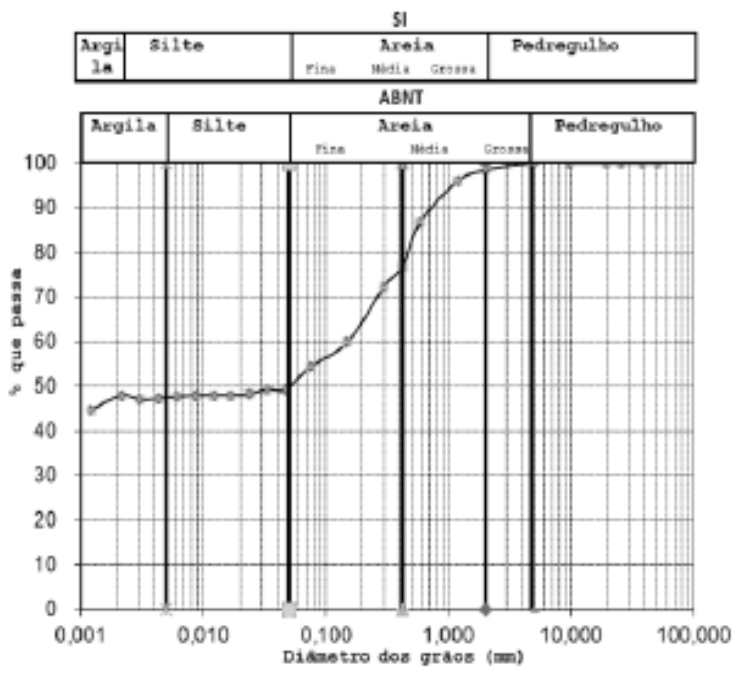

Fig. 12. Curva granulométrica do solo.

Tabela 4. Percentuais de pedregulho, areia, silte e argila do solo

\begin{tabular}{|c|c|c|c|c|}
\hline Amostra & $\begin{array}{c}\text { Pedregulho } \\
(\%)\end{array}$ & $\begin{array}{c}\text { Areia } \\
(\%)\end{array}$ & $\begin{array}{c}\text { Silte } \\
(\%)\end{array}$ & $\begin{array}{c}\text { Argila } \\
(\%)\end{array}$ \\
\hline Solo & 0,06 & 50,08 & 2,44 & 47,42 \\
\hline
\end{tabular}

\subsection{Limites de consistência}

O material de AR não apresentou limites de Atterberg, enquanto que o solo apresentou limite de liquidez (LL) igual a $41,05 \%$, limite de plasticidade (LP) igual a $20,70 \%$ e, portanto, índice de plasticidade (IP) igual a $19,90 \%$. O solo e o AR puderam ser classificado, então, serem classificados segundo o Sistema Unificado de Classificação dos Solos (SUCS) e o Transportation Research Board (TRB).

Tabela 5. Classificação do solo e AR segundo SUCS e TRB

\begin{tabular}{|l|l|l|}
\hline \multicolumn{3}{|c|}{ Classificação } \\
\hline Material & SUCS & TRB \\
\hline Solo & $\begin{array}{l}\text { CL - Argila de baixa } \\
\text { compressibilidade }\end{array}$ & A7-6 \\
\hline $\begin{array}{l}\text { Agregado } \\
\text { reciclado } \\
\text { misto }\end{array}$ & $\begin{array}{l}\text { SW- Areia bem } \\
\text { graduada }\end{array}$ & A-2 \\
\hline
\end{tabular}

\subsection{Massa específica}

Através do ensaio de massa específica, foram obtidos os resultados de 2,61 g/cm3 para o AR e 2,65 g/cm3 para o solo à temperatura de $20^{\circ} \mathrm{C}$. Estes resultados foram próximos dos valores encontrados por Macedo (2013) [10].

\subsection{Umidade ótima e massa específica seca máxima}

Através da análise das tabelas 6 e 7, percebe-se que, para ambas as energias de compactação aplicadas, houve uma diminuição da umidade ótima e aumento da massa específica seca máxima à medida que a porcentagem de $\mathrm{AR}$ aumenta nas composições. Esta tendência, contudo, não é observada para a compactação do agregado reciclado isolado, o que pode ser explicado pela significativa quebra dos grãos do agregado reciclado de alvenaria. $\mathrm{O}$ fenômeno aumenta a porcentagem de finos da amostra e, consequentemente, a taxa de absorção de água a medida que ele é compactado.

É importante ressaltar também que os resultados apresentados estão de acordo com a literatura, pois a mesma afirma que a presença de frações mais granulares em um material, quando estes se encontram compactados, indicam menores umidades ótimas e maiores pesos específicos (MACEDO, 2013). 
Compactaçeies Intermediárias

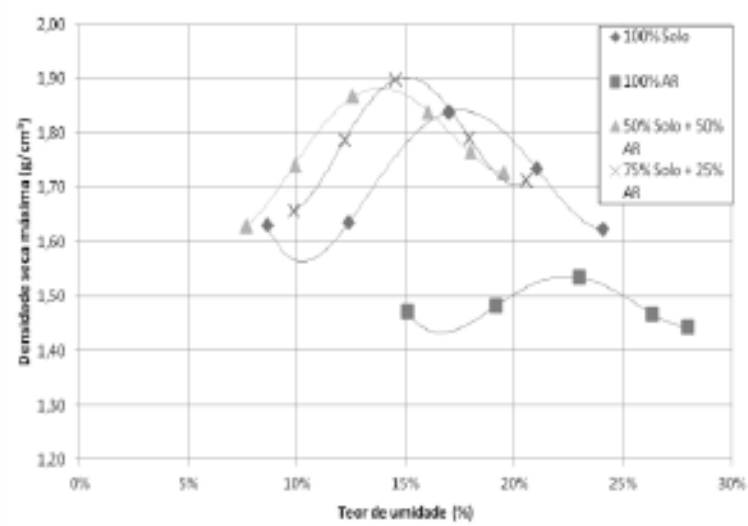

Fig. 13. Curvas de compactação para energia intermediária

Tabela 6. Resultados das compactações com energia proctor intermediária para as diferentes misturas

\begin{tabular}{|l|l|l|l|l|}
\hline Composições & Solo & $\begin{array}{l}\mathbf{2 5} \% \\
\mathrm{AR}\end{array}$ & $\begin{array}{l}\mathbf{5 0 \%} \\
\mathrm{AR}\end{array}$ & $\mathrm{AR}$ \\
\hline $\begin{array}{l}\text { Umidade } \\
\text { ótima (\%) }\end{array}$ & 18,96 & 14,74 & 14,24 & 22,96 \\
\hline $\begin{array}{l}\text { Massa } \\
\text { específica } \\
\text { aparente } \\
\text { seca máxima } \\
\left(\mathrm{g} / \mathrm{cm}^{\mathbf{3}}\right)\end{array}$ & 1,81 & 1,87 & 1,87 & 1,535 \\
\hline
\end{tabular}

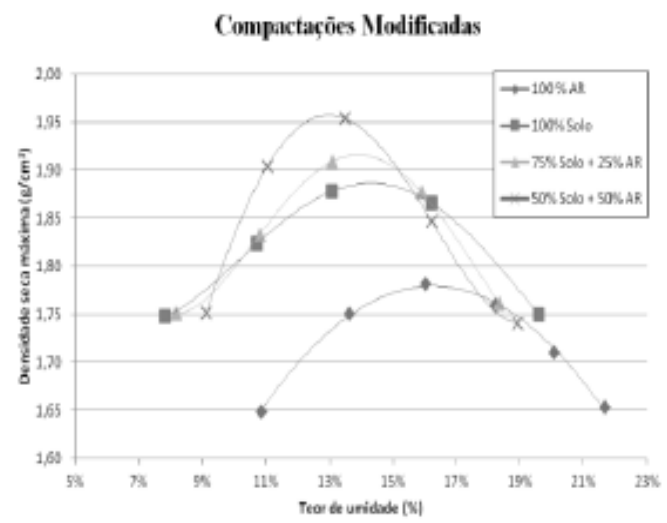

Fig. 14. Curvas de compactação para energia modificada.
Tabela 7. Resultados das compactações com energia proctor modificada para as diferentes misturas

\begin{tabular}{|c|c|c|c|c|}
\hline Composições & Solo & $\begin{array}{c}\mathbf{2 5 \%} \\
\mathrm{AR}\end{array}$ & $\begin{array}{c}\mathbf{5 0 \%} \\
\mathrm{AR}\end{array}$ & $\mathrm{AR}$ \\
\hline $\begin{array}{c}\text { Umidade } \\
\text { ótima (\%) }\end{array}$ & 14,59 & 14,24 & 12,76 & 16,13 \\
\hline $\begin{array}{c}\text { Massa } \\
\text { específica } \\
\text { aparente } \\
\text { seca máxima } \\
\left(\mathbf{g} / \mathrm{cm}^{3}\right)\end{array}$ & 1,88 & 1,91 & 1,95 & 1,78 \\
\hline
\end{tabular}

De acordo com Pinto (2006), um aumento da energia aplicada na compactação conduz a uma maior densidade seca máxima e uma menor umidade ótima de compactação, deslocando-se a curva para esquerda e para cima. Este efeito foi verificado nos ensaios realizados para as amostras de solo, agregado reciclado e as composições, sendo mais acentuados nas amostras com maior percentuais de AR [16] (figura 15). 


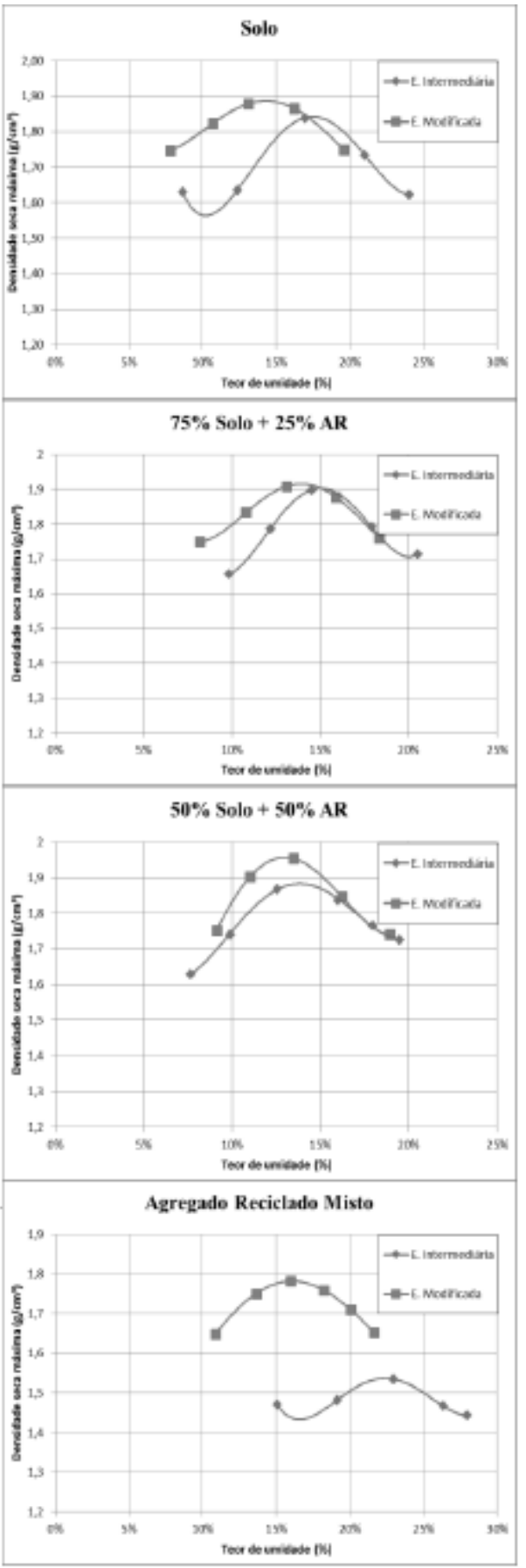

Fig. 15. Curvas com ener gias intermediária e modificada de compactação para as diferentes composições.

Os efeitos provocados pelo aumento da energia de compactação foram avaliados também por composição. $\mathrm{O}$ estudo das tabelas 8,9,10 e 11 mostra que a influência da energia de compactação no aspecto da umidade ótima e densidade seca máxima se sobressaiu nas composições unicamente de solo ou agregado reciclado.
Tabela 8. Resultados dos ensaios de compactação com energias intermediária e modificada para o solo

\begin{tabular}{|l|c|c|}
\hline $\begin{array}{c}\text { Energias de } \\
\text { compactação }\end{array}$ & $\begin{array}{c}\text { Umidade } \\
\text { otima }(\%)\end{array}$ & $\begin{array}{c}\text { Densidade } \\
\text { seca máxima } \\
\left(\mathrm{g} / \mathrm{cm}^{3}\right)\end{array}$ \\
\hline Intermediária & 18,96 & 1,81 \\
\hline Modificada & 14,59 & 1,88 \\
\hline $\begin{array}{l}\text { Acréscimo ou } \\
\text { diminuicão (\%) }\end{array}$ & $-23,05$ & 3,87 \\
\hline
\end{tabular}

Tabela 9. Resultados dos ensaios de compactações com energias intermediária e modificada da composição com $25 \%$ de AR

\begin{tabular}{|l|c|c|}
\hline $\begin{array}{c}\text { Energias de } \\
\text { compactação }\end{array}$ & $\begin{array}{c}\text { Umidade } \\
\text { ótima }(\%)\end{array}$ & $\begin{array}{c}\text { Densidade } \\
\text { seca máxima } \\
\left(\mathrm{g} / \mathrm{cm}^{3}\right)\end{array}$ \\
\hline Intermediária & 15,45 & 1,87 \\
\hline Modificada & 14,24 & 1,91 \\
\hline $\begin{array}{l}\text { Acréscimo ou } \\
\text { diminuição (\%) }\end{array}$ & $-7,83$ & 2,14 \\
\hline
\end{tabular}

Tabela 10. Resultados dos ensaios de compactação com energias intermediária e modificada para a composição com $50 \%$ de AR

\begin{tabular}{|l|c|c|}
\hline $\begin{array}{c}\text { Energias de } \\
\text { compactação }\end{array}$ & $\begin{array}{c}\text { Umidade } \\
\text { otima (\%) }\end{array}$ & $\begin{array}{c}\text { Densidade } \\
\text { seca máxima } \\
\left(\mathrm{g} / \mathrm{cm}^{3}\right)\end{array}$ \\
\hline Intermediária & 13,96 & 1,87 \\
\hline Modificada & 12,76 & 1,95 \\
\hline $\begin{array}{l}\text { Acréscimo ou } \\
\text { diminuição (\%) }\end{array}$ & $-8,60$ & 4,28 \\
\hline
\end{tabular}

Tabela 11. Resultados dos ensaios de compactação com energias intermediánia e modificada para o agregado reciclado

\begin{tabular}{|l|c|c|}
\hline \multicolumn{1}{|c|}{$\begin{array}{c}\text { Energias de } \\
\text { compactação }\end{array}$} & $\begin{array}{c}\text { Umidade } \\
\text { otima (\%) }\end{array}$ & $\begin{array}{c}\text { Densidade } \\
\text { seca máximana } \\
\left(\mathrm{g} / \mathrm{cm}^{3}\right)\end{array}$ \\
\hline Intermediária & 22,96 & 1,535 \\
\hline Modificada & 16,13 & 1,78 \\
\hline $\begin{array}{l}\text { Acréscimo ou } \\
\text { diminuição (\%) }\end{array}$ & $-29,75$ & 15,96 \\
\hline
\end{tabular}

\subsection{Resistência à compressão simples}

Para a energia intermediária, foram moldados corpos de prova com as composições $75 \%$ solo $+23 \%$ AR $+2 \%$ Cimento e $50 \%$ solo $+48 \%$ AR $+2 \%$ Cimento e estes foram rompidos aos 7 e 28 dias, enquanto que, para a energia modificada, foram moldados corpos de prova com a composição $50 \%$ solo $+48 \%$ AR $+2 \%$ Cimento para serem rompidos aos 7 dias.

As resistências a compressão simples foram obtidas pela média das tensões máximas suportadas pelos corpos de prova para cada mistura.

No que se refere às moldagens com energia intermediária de compactação, analisando a figura 16 , pode-se 
verificar que em ambas as misturas houve um acréscimo de resistência ao longo do tempo, assim como uma diminuição das deformações para uma mesma carga aplicada. O comportamento verificado se deve ao ganhos de resistência e rigidez oferecidos pelo processo de calcificação do cimento durante o período de cura.

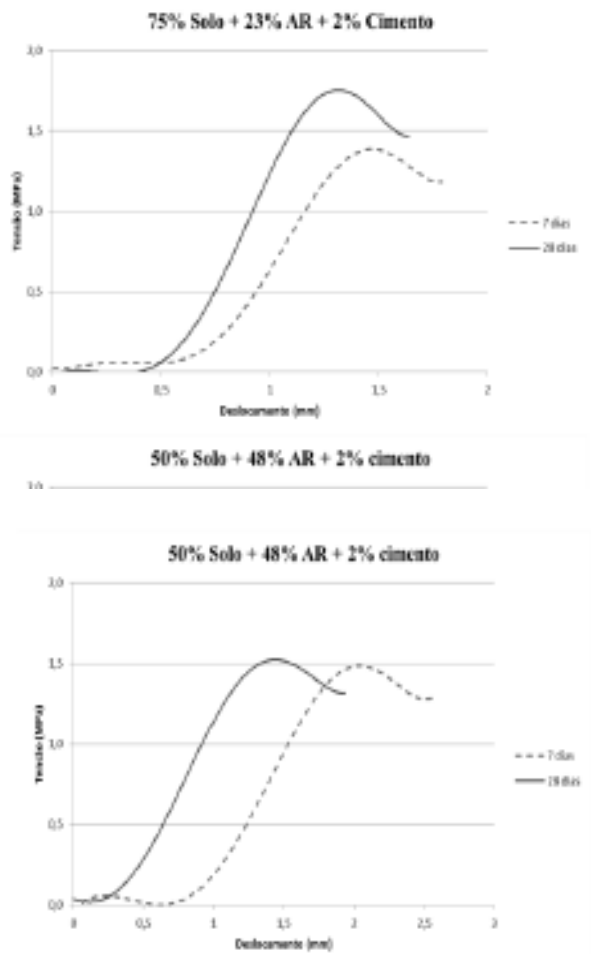

Fig. 16. Curvas de resistência à compressão das misturas aos 7 e 28 dias.

Pode-se verificar também, através da figura 17 e da tabela 12, um aumento de resistência mais significativo para os corpos de prova com a mistura $75 \%$ solo $+23 \%$ $\mathrm{AR}+2 \%$ cimento. De fato, este comportamento se verifica em materiais mais argilosos, devido ao maior teor de aglomerantes. Para a mistura com $50 \%$ solo $+48 \%$ AR + $2 \%$ cimento, o aumento de resistência com o tempo foi muito baixo. Isto demonstra, então, que o teor de cimento na mistura não foi suficiente para permitir um ganho relevante de resistência, assim como foi notado por Souza (2012) [22].

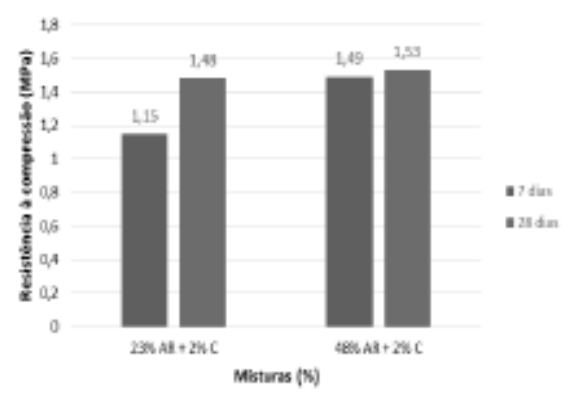

Fig. 17. Resistência à compressão das misturas aos 7 e 28 dias.

Tabela 12. Resistência à compressão dos corpos de prova para energia intermediária.

\begin{tabular}{|l|c|l|c|}
\hline \multicolumn{4}{|c|}{ Resistência à compressão (MPa) } \\
\hline Composição & $\begin{array}{l}\text { A0s } 7 \\
\text { dias }\end{array}$ & $\begin{array}{l}\text { Aos } \\
\mathbf{2 8} \\
\text { dias }\end{array}$ & $\begin{array}{l}\text { Acrésci } \\
\text { mo }(\%)\end{array}$ \\
\hline $\begin{array}{l}\mathbf{7 5} \% \text { solo }+23 \% \\
\mathrm{AR}+2 \%\end{array}$ & 1,15 & 1,48 & 28,70 \\
\hline $\begin{array}{l}\mathbf{5 0 \%} 5010+48 \% \\
\mathrm{AR}+\mathbf{2 \%} \% \text { cimento }\end{array}$ & 1,49 & 1,53 & 2,68 \\
\hline
\end{tabular}

Para a energia modificada de compactação, foram obtidos o resultados para a mistura com $48 \%$ de AR os quais estão apresentados na figura 18 e tabela 13 .

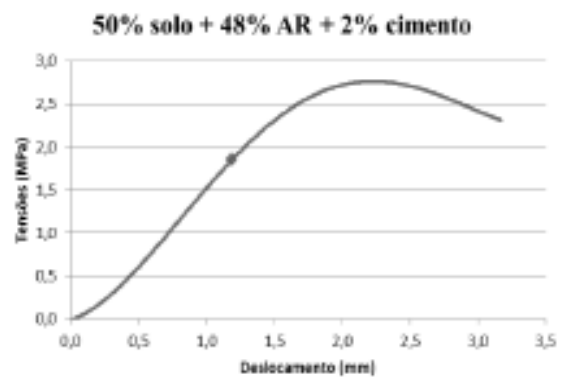

Fig. 18. Curva de RCS com energia modificada para a mistura com $48 \%$ de $A R$ aos 7 dias.

Tabela 13. Resistência para energia modificada da mistura com $48 \%$ de AR.

\begin{tabular}{c|c}
\multicolumn{1}{c|}{ Composição } & $\begin{array}{l}\text { Resistência a05 7 dias } \\
(\mathrm{MPa})\end{array}$ \\
\hline $\begin{array}{l}\mathbf{5 0 \%} \text { Solo + } 48 \% \mathrm{AR}+ \\
2 \% \text { Cimento }\end{array}$ & \multicolumn{1}{c}{2,76} \\
\hline
\end{tabular}

Considerando a figura 19 e tabela 14 , verificou-se que a mistura estudada apresentou um aumento significativo na resistência à compressão aos 7 dias com o aumento da energia aplicada na compactação, assim como um aumento da capacidade de deformação do material. 


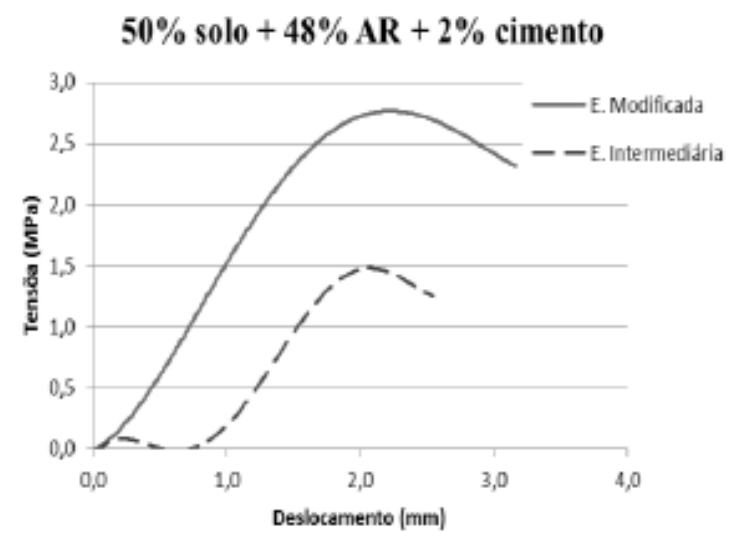

Fig. 19. Curvas de RCS para as energias intermediária e modificada da mistura com $48 \%$ de AR aos 7 dias.

Tabela 14. Resistências à compressão com energias intermediária e modificada para a mistura com $48 \%$ de AR aos 7 dias.

\begin{tabular}{|l|c|c|c|}
\hline \multicolumn{4}{|c|}{ Resistência à compressão aos 7 dias (MPa) } \\
\hline Composição & $\begin{array}{c}\text { E. } \\
\text { Interm } \\
\text { ediária }\end{array}$ & $\begin{array}{c}\text { E. } \\
\text { Modifica } \\
\text { da }\end{array}$ & $\begin{array}{c}\text { Acrésci } \\
\text { mo (\%) }\end{array}$ \\
\hline $\begin{array}{l}\mathbf{5 0} \% \text { solo + } \\
\mathbf{4 8} \% \text { AR }+ \\
\mathbf{2} \% \text { cimento }\end{array}$ & 1,49 & 2,76 & 85,23 \\
\hline
\end{tabular}

\section{Referências}

[1] P. C. Schenini, A. M. Bagnati e A. F. Cardoso, "Gestão de Resíduos da Construção Civil," Anais do Congresso Brasileiro de Cadastro Técnico Multifinalitário, pp. 1-13, 2004.

[2] ANTT, "Agência Nacional de Transportes Terrestres," 2002. [Online]. Available: www.antt.gov.br. [Acesso em Dezembro 2012].

[3] R. d. S. Motta, "Estudo laboratorial de agregado reciclado de resíduo sólido da construção civil para aplicação em pavimentação de baixo volume de tráfego," São Paulo, 2005.

[4] CONAMA, "Conselho Nacional do Meio Ambiente," Ministério do Meio Ambiente, 2002. [Online]. Available: http://www.mma.gov.br/port/conama/res/res02/res30702.html. [Acesso em 27 Outubro 2012].
[5] ABRELPE - Associação Brasileira de Empresas de Limpeza Pública e Resíduos Especiais, Panorama dos Resíduos Sólidos no Brasil, São Paulo, 2011.

[6] R. d. S. Motta, L. L. B. Bernucci e E. de Moura, "Aplicação de agregado reciclado de resíduo sólido da construção civil em camadas de pavimentos," XVII Congresso de Pesquisa e Ensino em Transportes, 2004.

[7] CPRH - Agência Estadual de Meio Ambiente, Plano Estadual de Resíduos Sólidos, 2012.

[8] F. d. C. Leite, "Comportamento mecânico de agregado reciclado de resíduo sólido da construção civil em camadas de base e sub-base de pavimentos," São Paulo, 2007.

[9] C. S. Poon e D. Chan, Construction and Building Materials, 8 ed., vol. 20, Hong Kong: Elsevier, 2006, pp. 578-585.

[10] T. F. Macedo, "Análise do desempenho mecânico da mistura agregado reciclado-solo-fibra-cimento para pavimentação," Recife, 2013.

[11] ABNT - Associação Brasileira de Normas Técnicas, NBR 11.578: Cimento Portland Composto Especificação, Rio de Janeiro, 1996.

[12] ABNT - Associação Brasileira de Normas Técnicas, NBR 7181: Solo - Análise Granulométrica, Rio de Janeiro, 1984.

[13] ABNT - Associação Brasileira de Normas Técnicas, NBR 6459: Solo - Determinação do Limite de Liquidez, Rio de Janeiro, 1984.

[14] ABNT - Associação Brasileira de Normas Técnicas, NBR 7180: Solo - Determinação do Limite de Plasticidade, Rio de Janeiro, 1984.

[15] ABNT - Associação Brasileira de Normas Técnicas, NBR 6508: Grãos de solos que passam na peneira de 4,8mm - Determinação da massa específica., Rio de Janeiro, 1984.

[16] C. d. S. Pinto, Curso Básico de Mecânica dos Solos em 16 aulas, $3^{\text {a }}$ Edição ed., São Paulo: Oficina de Textos, 2006. 
[17] ABNT - Associação Brasileira de Normas Técnicas, NBR 7182: Solo - Ensaio de Compactação, Rio de Janeiro, 1986.

[18] ABNT - Associação Brasileira de Normas Técnicas, NBR 12770: Solo coesivo - Determinação da resistência à compressão não confinada, Rio de Janeiro, 1992.

[19] ABNT - Associação Brasileira de Normas Técnicas, NBR 12025: Solo-cimento - Ensaio de compresssão simples de corpos-de-prova cilindricos, Rio de Janeiro, 1990.

[20] ABNT - Associação Brasileira de Normas Técnicas, NBR 15.115: Resíduos Agregados reciclados de resíduos sólidos da construção civil - Execução de camadas de pavimentação, Rio de Janeiro, 2004.

[21] ABNT - Associação Brasileira de Normas Técnicas, NBR 15116: Agregados reciclados de resíduos sólidos da construção civil - Utilização em pavimentação e preparo de concreto sem função estrutural - Requisitos, Rio de Janeiro, 2004.

[22] L. A. d. Souza, "Avaliação das propriedades do Resíduo da Construção Civil RCC como subsídio para confecção de tijolos de solo-cimento.," Recife, 2012.

[23] V. M. Corneli, “Análise da gestão de resíduos de construção e demolição no município de Campo Mourão/Paraná," Maringá, 2009. 